\title{
INFLUÊNCIA DA TERAPIA COMUNITÁRIA NA CULTURA MINEIRA
}

INFLUENCE OF COMMUNITY THERAPY IN MINAS GERAIS CULTURE

\author{
Doralice OTAVIANO ${ }^{1}$
}

RESUMO: De onde viemos, como nos relacionamos, o que fazemos tem origem em nossos familiares, pais, avós, bisavós, tataravós e assim por diante; somos frutos do meio em que vivemos e das nossas origens ancestrais. Ao estudo do homem em sua cultura denominamos antropologia cultural. Este artigo tem como objetivo apresentar a cultura mineira, como a terapia comunitária chegou neste estado e como ela influencia e é influenciada pelas pessoas desta região.

PALAVRAS-CHAVE: Terapia comunitária. Cultura. Minas Gerais.

ABSTRACT: Where we come from, how we relate, what we do originate in our relatives, parents, grandparents, great grandparents, great-grandparents and so on, we are products of the environment in which we live and of our ancestral origins. In the study of man in his culture we call cultural anthropology. This article aims to present Minas Gerais culture and how the community therapy arrived in this state and how it influences and is influenced by the people of this region.

KEYWORDS: Community therapy. Culture. Minas Gerais.

\section{As Minas Gerais}

"As montanhas escondem o que é Minas. Só os mineiros sabem e não dizem nem a si mesmos o irrevelável segredo chamado Minas. "'

Carlos Drummond de Andrade

O estado de Minas Gerais, conhecido por seu relevo montanhoso, é o quarto maior estado em extensão geográfica do Brasil e o segundo mais populoso do Brasil. Em seu território há o número recorde de 853 municípios, a maior quantidade dentre os estados brasileiros. Por ser um estado que faz divisa com vários outros, ele tem uma

${ }^{1}$ Doutora em terapia de casal e família - CAIFCOM Psicóloga. Especialista em musicoterapia - FPA, especialista em terapia de casal e família - UNIFESP. Terapeuta Comunitária e de Autoestima, formadora em TCI - Polo INTERFACI - SP. E-mail: doramusicoterapia.otaviano@gmail.com 
cultura peculiar e diferenciada, principalmente em seu sotaque, com mistura de mineiros, cariocas, paulistas, baianos, goianos, capixabas e mato-grossenses. Entretanto, em todas Minas Gerais, onde o pão de queijo pode variar de sabor e tamanho, há uma identidade regional que se identifica sempre pelo doce de leite na cozinha e pelo jeito especial de usar certas expressões, como 'trem' e 'uai', que estão na boca de todos. Muitas pessoas dizem que a montanha tem uma influência importante na religiosidade do povo mineiro. Talvez porque as montanhas estejam mais perto do céu ou pela bagagem cristã trazida pelos portugueses, que adotaram Minas como pátria, ou também pelos africanos de origem banto, que trouxeram a congada, uma manifestação religiosa negra com músicas e danças em homenagem à Nossa Senhora do Rosário. Como a religiosidade está sempre muito presente na história deste estado, muitos dizem que Minas Gerais é um dos estados mais religiosos do Brasil.

Eram mais de cem os grupos indígenas que viviam em Minas Gerais. Ao longo dos anos, eles foram sendo dizimados pelo homem branco, que os escravizava, matava, ocupava suas terras e transmitia-lhes suas doenças. Os Carijós, ou índios escravos, como eram chamados pelos colonizadores, foram pouco a pouco perdendo seu espaço. Com o tempo, desapareceram os Puris do sul de Minas, os Caiapós e os Bororós do oeste, dentre muitos outros.

A descoberta de ouro e, posteriormente, do diamante, provocou intenso fluxo migratório para Minas Gerais no fim do século XVII. A promessa de enriquecimento rápido atraiu pessoas de vários lugares do Brasil. Bandeirantes paulistas, “[...] na caça ao índio, ao ouro e às esmeraldas" (SILVA, 2005, p. 68), juntamente com baianos e pernambucanos, migraram e trouxeram consigo um grande contingente de negros africanos escravizados. A escravidão foi a forma dominante de organização do trabalho no surgimento da sociedade mineira (RAMOS, 1996). A necessidade de mão-de-obra para a exploração mineral e a ávida corrida pelo ouro durante a primeira metade do século XVIII fizeram com que o valor de um negro escravo na região fosse muito maior que no restante do país.

Segundo Vasconcelos (1974), da mistura entre negros e brancos surgiram os mulatos artistas tocando flautas, violinos, órgãos e misturando as músicas sacras da igreja com as músicas profanas tocadas nas ruas das cidades históricas.

Os encontros de diversas culturas, como a dos africanos, portugueses, judeus vindos do norte de Portugal, baianos, pernambucanos, bandeirantes paulistas, sulistas, 
todos de passagem em busca do ouro, deixaram suas heranças na mineiridade que se perpetua (IGLESIAS, 1985).

A história contribui muito para a constituição do jeito de ser de um povo. Segundo Barreto (2005), a necessidade de sobrevivência levou o homem a viver em grupo e a adequar suas diferenças étnicas em seu espaço.

O mineiro é desconfiado, calado. Este comportamento pode ter reflexo em sua história secular. No auge da produção de pedras preciosas no estado, falar era artigo de luxo para poucos da coroa portuguesa. Assim, segredos e sussurros faziam parte da cultura; nesta época, falar era prata e o silêncio era ouro. As consequências por falar algo que comprometesse os negócios da coroa poderiam ser drásticas, por isso, a melhor forma de sobrevivência na época foi falar pouco, guardar segredo e observar. Até hoje há um dito popular que diz "quem fala muito dá bom dia a cavalo". Outro afirma que "o mineiro quando sai de dentro da mata sai de costas, assim, quem o vê saindo pensa que ele está entrando". Apesar disso, o mineiro também é hospitaleiro, receptivo, amante da liberdade, religioso, tradicionalista (ABDALA, 2006).

Talvez o jeito mineiro seja muito mais do que o jeito tranquilo e agradável de falar. É o jeito de se expressar, de se fazer representar. O jeito mineiro vai além do tradicional pão de queijo, vai além das diversas igrejas e imagens tombadas como patrimônio cultural, vai além da arquitetura. Influenciados por diversos costumes construídos ao longo do tempo e das relações sociais, e apurados pelas fronteiras com outros estados, os mineiros foram construindo seus hábitos. Pela história de lutas silenciosas o povo mineiro se tornou resiliente. Para Carlos Drummond de Andrade (2013, s/p. [online]):

Ser Mineiro é não dizer o que faz, nem o que vai fazer, é fingir que não sabe aquilo que sabe, é falar pouco e escutar muito, é passar por bobo e ser inteligente, é vender queijos e possuir bancos. Um bom Mineiro não laça boi com embira, não dá rasteira no vento, não pisa no escuro, não anda no molhado, não estica conversa com estranho, só acredita na fumaça quando vê o fogo, só arrisca quando tem certeza, não troca um pássaro na mão por dois voando. Ser Mineiro é dizer "uai", é ser diferente, é ter marca registrada, é ter história. Ser Mineiro é ter simplicidade e pureza, humildade e modéstia, coragem e bravura, fidalguia e elegância. Ser Mineiro é ver o nascer do Sol e o brilhar da Lua, é ouvir o canto dos pássaros e o mugir do gado, é sentir o despertar do tempo e o amanhecer da vida. Ser Mineiro é ser religioso e conservador, é cultivar as letras e artes, é ser poeta e literato, é gostar de política e amar a liberdade, é viver nas montanhas, é ter vida interior, é ser gente. 
As contribuições dos costumes judeus na cultura mineira foram inúmeras, dentre elas o casamento com consanguíneos por longas gerações, desde os tataravôs, bisavós, avós e pais. Era comum os pais escolherem o noivo ou a noiva para seus filhos. Há também a tradição de não jogar nada fora e aproveitar tudo, assim não há desperdício. Outra tradição local: no final de um funeral, ao se enterrar o corpo, é de costume jogar um punhado de terra sobre o caixão quando este é descido à sepultura. Além disso, o emprego do verbo 'judiar' vem do tempo da Inquisição, quando maltratavam e perseguiam os judeus; esta tem o sentido de torturar, atormentar.

As línguas africanas influenciaram a maneira de falar do povo mineiro. Dizem que a língua banta tem uma estrutura parecida à da língua português, devido ao uso de muitas vogais e sílabas nasais ou abertas, como podemos perceber nas palavras: moleque, fuxico, quitute, quiabo, senzala, corcunda, cacunda, quizomba, bagunça, curinga, dengo, gangorra, cachimbo, fubá, macaco e quitanda. A literatura popular de origem africana é riquíssima, e está presente nos contos que hoje integram o folclore mineiro. Deste modo, temas como assombração, mulher de branco e lobisomem compõem o imaginário popular.

De acordo com Strecker (2006 [on line]), uma das lendas é a Procissão das Almas: um fato muito estranho aconteceu na cidade de Congonhas. Uma senhora na janela, de madrugada, observava a cidade em silêncio. Ela morava na ladeira do Bom Jesus, completamente deserta até certa hora, quando ela avistou pessoas que subiam em procissão. Eram pessoas desconhecidas, que ela nem sequer vira algum dia, nem no centro, nem na rua, e muito menos na Igreja. Mas uma dessas pessoas lhe entregou uma vela e pediu para guardar até o outro dia. Ela aceitou e guardou numa gaveta de seu quarto. Quando voltou à janela, a procissão já ia mais adiante. Foi quando ela notou que as pessoas não caminhavam, pois não possuíam pés: elas flutuavam! E o seu espanto só não foi maior do que quando resolveu olhar a vela guardada: havia se transformado em um pedaço de fêmur humano.

A herança portuguesa está presente nas igrejas católicas, nos conjuntos arquitetônicos religiosos de Minas Gerais, no culto ao Divino e a São Gonçalo de Amarante, santo padre português, cuja imagem brasileira tem as características de um violeiro. Há também esta presença nos grupos religiosos das folias ou bandeiras e o da recomenda de almas (MORAES, 1979).

Em Minas Gerais, a cozinha é o lugar da casa mais importante, pois neste espaço as pessoas têm a possibilidade de se encontrar para comungar algo, o alimento, e ainda 
podem conversar aos pés de um bom fogão de lenha, que além de esquentar a casa alegra o coração e a alma das pessoas. Segundo Abdala (2006), as panelas são de pedrasabão, de barro e de ferro e os pratos típicos desta culinária são: tutu, pão de queijo, torresminho, couve e muito mais! Comida mineira tem perfume, aroma, sabor, tem cor.

Chão de cimento queimado, fogão construído a partir de técnicas tradicionais, quando não feito a partir dos cupinzeiros que surgem nos pastos ou de latões embutidos nas grossas paredes de adobe. Linguiças ou carnes defumando, penduradas. Chaminé ativa, fumaça subindo pelo céu, avisando com seu aroma típico da roça que há quitandas ou 'comidas de angu' esperando os comensais.

As contribuições étnicas que vêm de diversas culturas fazem a comida mineira ser tão saborosa. Dos índios veio o escaldado, o pirão, a paçoca, as farofas, os pratos à base de mandioca e de milho que se derivaram para as canjicas, mingaus e papas. Dos portugueses proveio a utilização do ovo da galinha, que propiciou um farto rendimento culinário: fritadas, doces, bolos, ovos cozidos, estrelados, quentes, moles, baba-demoça, doce de ovos, fios de ovos e gemada com vinho do Porto. O açúcar conquistou todos. As africanas começaram a trabalhar nas cozinhas dos senhores de engenho e introduziram novas técnicas de preparo e tempero dos alimentos. Também adaptaram seus hábitos culinários aos ingredientes do Brasil. Assim, foram incorporados aos hábitos alimentares dos brasileiros o angu, o cuscuz, a pamonha e a feijoada, nascida nas senzalas e feita a partir das sobras de carnes das refeições que alimentavam os senhores; o uso do azeite de dendê, leite de coco, temperos e pimentas e de panelas de barro e de colheres de pau. Os traficantes de escravos também trouxeram para o Brasil ingredientes africanos, como é o caso da banana, ícone de brasilidade mundo afora, e da palmeira, de onde se extrai o azeite de dendê.

Os sertanejos, caçadores, romeiros, tinham na rapadura com farinha uma provisão nacional. O lombo, a leitoa e a galinha assados eram pratos de festa, de domingo, de visitas. Na intimidade do dia a dia, os cozidos predominavam: o feijão, o angu, o mexido, verduras e legumes cozidos, ou os legumes com carne, frango com quiabo, por exemplo, mandioca e canjiquinha com carne, podendo ser costela ou suã de porco, costela de vaca e outros. Leite em abundância, queijos variados e ovos possibilitaram a ampliação das quitandas e doces - legados da tradição portuguesa. A canjica com leite era sobremesa constante nas fazendas e, em algumas casas, era a ceia mais apreciada antes de se deitar. Com o acréscimo do amendoim, fez-se a nossa canjica. A carne de vaca se tornou mais presente na mesa mineira, mas demorou um 
século para substituir o costume de consumir, preferencialmente, carne de frango e de porco, que ainda hoje predominam nos pratos típicos. A presença do café também se tornou definitiva. O bule no fogão a lenha é um forte elemento do cenário da cozinha mineira, onde o café, sempre quentinho, era servido acompanhando as quitandas, no encerramento das refeições, ou na primeira refeição do dia, adoçado com rapadura.

O folclore mineiro é muito rico, afinal, Minas é um estado que reúne muitas culturas, por ser tão acolhedor e abrigar hábitos e costumes bastante pitorescos. Citaremos festas e manifestações folclóricas, mas somente falaremos de três de maneira ampliada. Elas foram trazidas pelos índios, negros e portugueses. A religiosidade tem influência marcante nas principais manifestações culturais do povo mineiro, principalmente nas festas folclóricas, além das tradicionais festas juninas e da folia dos reis, destacam-se a Festa do Divino, o congado e a cavalhada. As festas cíclicas são aquelas que aparecem conforme o ciclo folclórico: Natal, Carnaval, Quaresma, Divino, Juninas e Rosário. Danças Batuque, Lundu, São Gonçalo (de promessa) em Januária, Cateretê (Catira), Caxambu de cultura Banto. Dança dos Velhos (semelhante à do Rio de Janeiro e São Paulo), Mineiro-Pau, Zona da Mata (dança de roda ao som de chocalhos, pandeiro, reco-recos, ferrinhos e caixas), Folia de Reis, o Boi (Boi de Manta, Boi-Janeiro, Boi-Marruá) - com características mineiras.

Surgida no Brasil com a vinda forçada de povos africanos de origem banto, oriundos das regiões do Congo (daí o nome congada), Moçambique, Angola, entre outras, a congada é uma manifestação característica da cultura afro-brasileira, que encontrou no sincretismo religioso um meio de resistir ao domínio e à imposição etnocêntrica dos valores culturais e religiosos do homem branco. Segundo Capitão (2010, s/p. [online]),

O Congo é uma importante expressão da cultura tradicional brasileira. Festa popular que tem origem no catolicismo e nas sangrentas histórias de guerra do povo africano. No Brasil, as festas em homenagem a Nossa Senhora do Rosário são comuns, porém cada região mantém o rito de forma particular. A origem dessa devoção vem de uma lenda sobre o aparecimento da imagem de Nossa Senhora à beira da água, sendo então cultuada por um escravo. Uma variação da congada é o Moçambique, que ocorre nas Festas de Nossa Senhora do Rosário e São Benedito.

A folia de Reis é uma festa católica que celebra os Três Reis Magos e tem como referência o nascimento de Jesus Cristo em 25 de dezembro. Os festejos de Natal eram comemorados por grupos que visitavam as casas tocando músicas alegres em louvor aos 
'Santos Reis' e ao nascimento de Cristo. Essas manifestações festivas estendiam-se até a data consagrada aos Reis Magos, 06 de janeiro.

Caiapós é uma dança dramática, ou folguedo, de inspiração ameríndia, realizada durante festas religiosas. Segundo Lima, apareceu no estado de São Paulo e em regiões limítrofes de Minas Gerais. Consiste num cortejo de participantes alinhados dois a dois, que dançam pelas ruas tendo à frente o cacique. Este leva a tiracolo uma buzina de chifre. Eles usam arco e flecha, e de vez em quando interrompem o desfile, executando saltos característicos da dança em louvor ao cacique.

Catira ou Cateretê, como também é conhecida, é uma dança rural característica do sudeste do Brasil, apesar de já ter sido encontrada em estados da região sul e centrooeste, sendo observada desde o período colonial (CASCUDO, 2012). Existem muitas controvérsias sobre sua origem, uns acreditam ser indígena, outros africana, ou até mesmo europeia. Borges (2009) realizou um estudo que apresenta as possíveis influências que cada um destes povos pode ter representado no desenvolvimento da catira, fazendo um apanhado histórico das contribuições tupi, lusitana, espanhola e africana.

\section{Terapia comunitária em Minas Gerais}

A Terapia Comunitária nasceu na década de 1990 no Brasil. Foi criada pelo Prof. Dr. Adalberto de Paula Barreto: nordestino, habituado com as pessoas humildes com quem convivia em Canindé, cidade das romarias, viveu imerso “[...] num mundo mágico-religioso, marcado por uma maneira de viver que se caracterizava pela cura dos doentes e dos infelizes" (BARRETO, 2005, s/p).

Constitui-se numa roda de partilha de experiências e sabedoria, na qual o acolhimento e o respeito ao outro são fundamentais. Nesse processo, todos são corresponsáveis na busca de soluções para sofrimentos e problemas do cotidiano. Todos os comentários são relevantes e incluídos no grupo. Há o fortalecimento dos vínculos sociais e os conflitos são redimensionados. Os preconceitos e os estereótipos são quebrados. Há a reconquista de espaços comunitários saudáveis, nos quais são encontrados valorização, aconchego e confiança. Há a troca de vivências e sentimentos, como também a partilha de canções, provérbios, poesias, lendas; tudo é material que 
enriquece os grupos de trabalho e faz de cada um deles uma experiência única e marcante.

A cultura é um elemento fundamental na construção da identidade de um povo, interferindo diretamente na definição de quem eu sou e quem somos nós, e quando isto acontece num momento de roda acessa diretamente o sistema límbico do córtex cerebral, trazendo lembranças esquecidas àquele indivíduo que faz parte deste momento de roda.

Em Minas Gerais, a terapia comunitária está presente desde 2004 e tem contribuído para a saúde mental em diversos setores da sociedade: hospitalar, social, educacional, religioso, rural. Muitos terapeutas comunitários que foram formados pelos polos contribuem para o desenvolvimento e expansão da prática neste estado. Como diz Adalberto Barreto, nosso salário afetivo está garantido, pois para ser um formador devese ter amor pela profissão, tem que gostar de gente, e acima de tudo não ter medo. Falar sobre a cultura do povo mineiro cumpre exatamente um dos eixos teóricos da terapia comunitária: antropologia cultural, o estudo do homem em seu espaço. Procura-se descrever neste artigo a origem, a história, etnia, e jeito de ser deste povo tão especial que é o povo das Minas Gerais.

\section{Como é ser terapeuta comunitário mineiro}

Por Maria Lucia de Andrade Reis e Greice Mara Mendes Caicó, do sul de Minas:

Uai... quando sobre terapia comunitária integrativa ouvimos falar, ficamos na expectativa deste trem compartilhar, pois é, mineiro, além de queijo, gosta de conversar. Atravessamos o país e chegamos no nordeste, para uma cabra da peste sobre ela nos ensinar. De volta pra Minas Gerais abrimos as portas para ela entrar. Desfizeram-se em prosa, colares de dores, pois mineiro sabe bem prosa.

Roda aqui, roda acolá, no posto de saúde e na fundação, a comunidade vem participar. E dona Antônia? É bom desabafar o coração! Sem contar a alegria quando há formação. Um terapeuta desabrochando, mais um garimpeiro garimpando pérolas. Indo por Minas inteiras, de roda em roda, cidade e sertão. Todo dia há um esforço para que a teia mineira possa aumentar. Conversas e mais conversas, todas de pé de ouvido. Gratificante ver a teia crescer, terapeuta mineira, escolha melhor não podia ter tido. 
Figura 1: Roda de terapia comunitária

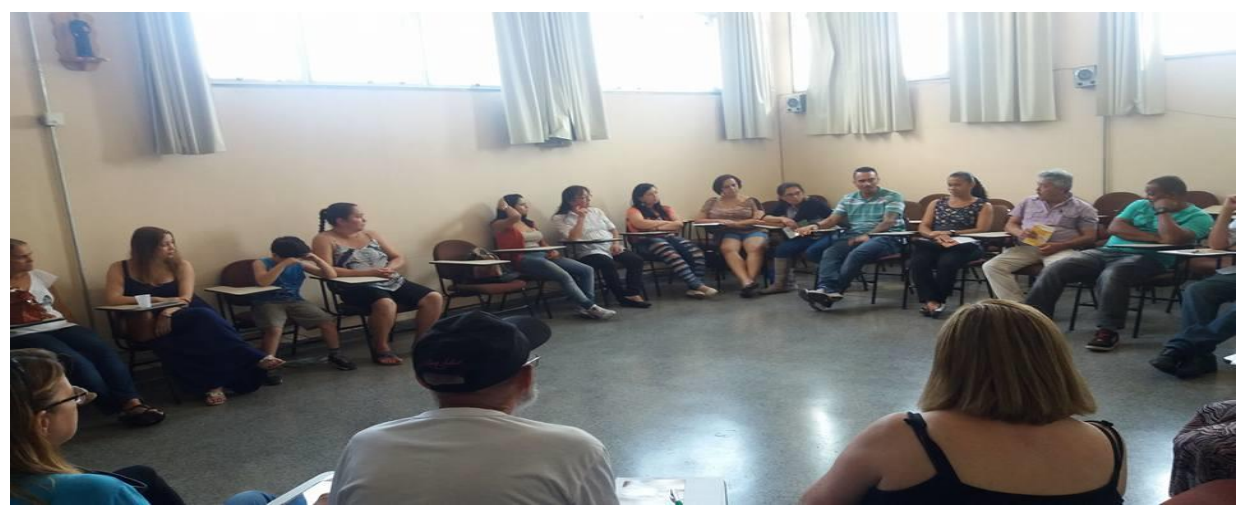

Fonte: Arquivo pessoal.

\section{Contribuições da cultura mineira para a Terapia Comunitária}

A seguir, serão destacas algumas contribuições da cultura mineira à terapia comunitária. Músicas mineiras adaptadas para terapia comunitária:

\section{Peixe vivo: ${ }^{2}$}

Como pode um indivíduo viver sempre em agonia.

Como pode um indivíduo viver sempre em agonia.

Como poderei viver, como poderei viver, sem a minha, sem a sua,

Sem a nossa companhia, sem a minha, sem a sua, sem a nossa terapia.

\section{Catira: ${ }^{3}$}

No alto da laranjeira, tem um ninho de barro.

Pode ser do João, João de Barro, pode ser do João, João de Barro.

Catira... Sabiá laranjeira, tem o peito dourado, voa fazer canção para os namorados, Voa fazer canção para os namorados. Queria ser passarinho, para poder olhar pra baixo,

Ver tudo pequenininho, casa, cavalo e riacho.

Ver tudo pequenininho, casa, cavalo e riacho.

${ }^{2}$ Domínio Público.

${ }^{3}$ Domínio Público. 


\section{Está caindo fulo: ${ }^{4}$}

Lá na rua debaixo, lá no fundo da horta

A polícia me prende, lelé

A Rainha me solta.

Está caindo fulo, eh (bis)

Lá do céu, cai na terra. Ai meu Deus, está caindo fulo.

\section{Faz doce Sinhá Maria: 5}

Da abóbora faz melão, do melão faz melancia (bis)

Faz doce sinhá, faz doce sinhá, quem quiser aprender dançar,

Vai à casa do Juquinha (bis)

Ele pula, ele roda, ele dá uma quebradinha.

\section{Considerações Finais}

O mundo passa por momentos de transformações rápidas, nas quais a tecnologia tem sua participação fundamental, contribuindo para descobertas magníficas na cura de várias doenças importantes, por exemplo; entretanto, como a moeda tem duas faces, deixa sua marca negativa: um isolamento social importante. Isto não é diferente em outros estados, mas observamos que a população mineira vem adoecendo solitariamente e consideramos que a cultura da prosa, da conversinha no portão, do compartilhar do dia a dia, vem sendo trocado pela desconfiança, pelos muros, pela televisão e pelo medo.

A cultura mineira se revitaliza e se renova pelo caminho da terapia comunitária, que tem o papel primordial de contribuir para o equilíbrio e o bem-estar das pessoas da comunidade de modo simples. Além disso, resgata valores muito conhecidos, mas um pouco esquecidos, e permite que todos que desejam buscar inspiração na vida possam usar de modo apropriado as ferramentas da terapia comunitária para poder viver melhor.

A terapia comunitária chegou em Minas Gerais em 2004, primeiramente pelo Movimento Integrado de Saúde Comunitária de Minas (MISC Minas). Em 29.01.2007, o mesmo foi registrado como uma associação sem fins lucrativos. Cumpre seus

${ }^{4}$ Domínio Público.

${ }^{5}$ Domínio Público. 
objetivos realizando as seguintes atividades: cursos de formação gerais, cursos de formação de multiplicadores do Programa Resgate da Autoestima na Comunidade (Cuidando do Cuidador); além disso, realiza rodas em diversas instituições e comunidades.

Em 2009, nasce o MISC dos Vales (Movimento Integrado de Saúde Comunitária de Governador Valadares), designado como Polo Formador em Terapia Comunitária Integrativa. Desde então promove cursos de capacitação em terapia comunitária em Minas Gerais e no Espírito Santo. Entre suas atividades estão: oficinas de cuidado, rodas de TCI, cursos de capacitação em TCI e técnicas do Resgate da Autoestima (Cuidando do Cuidador). No mesmo ano, o Instituto Afinando a vida (IAV) iniciou suas atividades de formação em terapia comunitária na cidade de Guaxupé - MG. O instituto exerce suas funções em Minas Gerais e São Paulo e tem como objetivos aprimorar a convivência humana, resgatar o potencial criador dos indivíduos, desenvolver ações educativas e articulação dos saberes, redescobrindo por meio da música a essência do aprender a viver.

Em setembro de 2010 chega em Pouso Alegre o Centro de Ensino e Pesquisa e Atendimento do Indivíduo, Família e Comunidade (Caifcom, sul de Minas) que desenvolve as seguintes atividades: oficinas de cuidado, rodas de TCI, cursos de capacitação em TCI e técnicas do Resgate da Autoestima (Cuidando do Cuidador), além de promover workshop de Técnicas para Redução de Estresse (TRE).

\section{REFERÊNCIAS}

ABDALA, Mônica Chaves. Sabores da tradição. Revista do arquivo público mineiro, Ano XLII, n. 2, p. 119-130, jul/dez. 2016.

BARRETO, Adalberto de Paula. Terapia comunitária passo a passo. Fortaleza: Gráfica LCR, 2005.

CAPITÃO, Antônio Júlio. Encontro teca. Disponível em: $<$ http://www.encontrodeculturas.com.br/encontroteca/grupo/terno-defagundes\#.VQ75Iia5cdU>. Acesso em: 10 nov. 2016.

DINIZ, Irila. Catira. Disponível em: <http://dancanaefe.blogspot.com.br/p/catira.html>. Acesso em: 10 nov. 2016.

DRUMMOND DE ANDRADE, Carlos. Ser mineiro. Disponível em: $<$ http://www.itatiaia.com.br/blog/jose-lino-souza-barros/ser-mineiro-carlos-drummondde-andrade>. Acesso em: 10 nov. 2016. 
GUIMARAES, Marcelo M. Algumas famílias mineiras, tradições e costumes. Disponível em: <http://anussim.org.br/algumas-familias-mineiras-tradicoes-ecostumes >. Acesso em: 20 nov. 2016.

IGLESIAS, Francisco. Três séculos de Minas Gerais. Belo Horizonte: Biblioteca pública estadual Luiz de Bessa, 1985.

LENDAS DE CONGONHAS. Procissão das almas. Domínio público. Disponível em: $<$ http://www.descubraminas.com.br/Cultura/CasoMinasDetalhe.aspx?cod_casocategori $\mathrm{a}=2 \&$ cod_caso $=54>$. Acesso em: 20 nov. 2016.

MORAES FILHO,Neto. Festas e tradições populares no Brasil. São paulo Edusp/ Itatiaia, 1979

POVOS indígenas em Minas Gerais. Disponível em: <http://www.descubraminas.com.br/MinasGerais/Pagina.aspx?cod_pgi=1814>. Acesso em: 10 set. 2016.

QUEIJO Minas: um patrimônio da cozinha mineira. Disponível em: $<$ http://www.petitgastro.com.br/queijo-minas-um-patrimonio-da-gastronomiamineira/>. Acesso em: 10 nov. 2016.

ROSSINI TAVARES, Lima. Caiapós. Disponível em: <http://dancasfolcloricas.blogspot.com.br/2011/03/caiapos.html>. Acesso em: 10 nov. 2016.

SILVA. A história da presença negra em Minas Gerais. Disponível em: <http://www.cpisp.org.br/comunidades/html/brasil/mg/mg_historia.html>. Acesso em: 10 nov. 2016.

STRECKER, Heidi. Vocabulário brasileiro: culturas africanas influenciaram nosso idioma. Disponível em: <https://educacao.uol.com.br/disciplinas/culturabrasileira/vocabulario-brasileiro-culturas-africanas-influenciaram-nosso-idioma.htm>. Acesso em: 20 nov. 2016.

VASCONCELOS, Diogo. História antiga de Minas Gerais. Belo Horizonte: Itatiaia 1974.

\section{Como referenciar este artigo}

OTAVIANO, Doralice. Influência da terapia comunitária na cultura mineira. Revista Temas em Educação e Saúde, Araraquara, v. 12, n. 2, p. 163-174, jul-dez. 2016. ISSN: 1517-7947.

Submetido em: $30 / 10 / 2016$

Aprovado em: 30/11/2016 